\title{
The Value Relevance of Revenue Recognition under International Financial Reporting Standards
}

\author{
Karina Kasztelnik ${ }^{1}$ \\ ${ }^{1}$ Chair, Dissertation Committee, Professor Accounting \& Tax, Grand Canyon University - College of Doctoral \\ Studies - DC Network, United States \\ Correspondence: Karina Kasztelnik, Chair, Dissertation Committee, Professor Accounting \& Tax, Grand Canyon \\ University - College of Doctoral Studies - DC Network, United States. E-mail: karinakasztelnik@yahoo.com
}

Received: July 4, 2015

Accepted: August 2, 2015

Online Published: August 5, 2015

doi:10.5430/afr.v4n3p88

URL: http://dx.doi.org/10.5430/afr.v4n3p88

\begin{abstract}
This study examines if there has a major change in the value relevance of revenue recognition components since the adoption of International Financial Reporting Standards 15 in the United States. The research problem addressed the lack of understanding of the value relevance of revenue recognition under IFRS and its application to impact for the telecommunication industry. Our results show that the public firms revenue recognition are value relevant under United States of Generally Accepted Accounting Principles (US GAAP) and remain so after the adoption of IFRS. Also, for revenue recognition after IFRS, along with an increase in the value relevance in the future. These results are consistent with the proportion that revenue recognition plays a reinforcing role that complements the more complex IFRS accounts. Consequently, if the International Accounting Standards (IASB) were to mandate revenue recognition, it would, in all likelihood, provide users of accounts with a valuable incremental source of hard international transaction information.
\end{abstract}

Keywords: Revenue Recognition and International Financial Reporting Standards, Product

\section{Introduction}

Revenue Recognition, Services Revenue Recognition, IFRS revenue recognition value relevance The International Accounting Standards Board (IASB) and Financial Accounting Standards Board (FASB) completes a joint effort to improve financial reporting by creating a common revenue standard for IFRS and US GAAP that can apply consistently across various transactions, industries and capital markets. In IFRS 15 and Topic 606, the boards achieved their goal of reaching the same conclusions on all requirements for the accounting for revenue from contracts with customers.

However, there are some minor differences are follows: (a) Collectability threshold 50\% under IFRS 15 and $70 \%$ under US GAAP; (b) Interim disclosure requirements - IAS 34 Interim Financial Reporting will apply to revenue from contracts with the customer. They require a public entity to disclose disaggregated revenue information in interim financial reports. US GAAP, Topic 270 Interim Financial Reporting will apply to revenue from contracts with the customer. They require a public entity to disclose disaggregated revenue information in interim financial reports and require information about both contract balances and remaining performance obligations to disclose on an interim basis; (c) Early application and effective date - allows entities to apply the requirements early, whereas Topic 606 prohibits a public entity from applying the requirements earlier than the effective date. In addition, the effective date for IFRS 15 is for annual reporting beginning on or after 1 January 2017, whereas Topic 606 has an effective date for public entities for annual reporting periods beginning after 15 December 2016; (d) Impairment loss reversal - paragraph 104 of IFRS 15 requires an entity to reverse impairment losses, which is consistent with the requirements for the impairment of assets within the scope of IAS 36 Impairment of Assets. In contrast, consistent with other areas of US GAAP, Topic 606 does not allow an entity to reverse an impairment loss on an asset that is recognized in accordance with the guidance on costs to obtain or fulfil a contract; ( e) Non-public entity requirements - there are no specific requirements included in IFRS 15 for non-public entities. Entities that do not have public accountability may apply IFRS for Small and Medium-sized Entities. At the same time, Topic 606 stays the same for public and non-public entities. 
The new standard includes extensive disclosure requirements applicable to all companies. The new disclosures are onerous and may require disclosure of information that could be commercially sensitive. Examples of new disclosures include the reconciliation of contract asset and contract liability balance. Transaction price and when revenue recognitions are allocated to performance obligations that are unsatisfied or partially satisfied for instance, future order books for which the company has signed contracts with customers for future deliveries including when the future order books are expected to recognize as revenue. Closing balances of assets recognized from the costs to obtain or fulfill a contract with a customer by category for example, costs to obtain contracts, pre-contract costs and set up costs. Understanding, the extent of disclosures in advance will enable companies to redesign existing systems to capture the additional information required for disclosure and to assess the impact on the business if the disclosures include commercially sensitive information.

Using a sample of non-financial companies listed on the US Security Exchanges Commission (SEC) 100 from 2005 - 2015 we examine whether there has been a change in the value relevance of revenue recognition statement under IFRS relative to United State Generally Accepted Accounting Principle (US GAAP).

Our results show that for the public firms' revenue recognition statements are value relevant under US GAAP and remain so after the adoption of IFRS. Also, for public firms there is a significant increase in the value relevance of revenue recognition after IFRS, along with an increase in the value relevance of accruals. These are consistent with the proposition that revenue recognition play a reinforcing role that complements the more complex IFRS accounts. Consequently, if the IASB were to mandate revenue recognition statement it would likely provide users of accounts with a valuable incremental source of hard transaction information.

\section{Research Question}

The following research questions guided this study:

1.) What is the relationship between pre-IFRS operating income and post-IFRS operating income in the multinational companies, Verizon, in the telecommunication industry?

2.) What is the relationship between pre-IFRS operating income and post-IFRS operating income in the multinational companies, AT\&T, in the telecommunication industry?

\section{Limitations}

The limitation of this study involves the major selection of an ex post facto study design consisting of a sample of two international corporations. This approach created the limits of the representativeness of the sample and generalizability of the study. A second limitation of this study inherently related to the research methodology of using available data and author manipulation of the data. The most potential source of error using the selected methodology is the availability and accuracy of the data itself and correct calculation of measures derived by the author this article. The author attempted to minimize this source of potential error by exploring records only from the official public records from the selected companies and avoided author calculations when possible.

\section{Literature Review}

\subsection{Prior Research on Revenue Recognition}

"The major revenue line item on the income statement is typically the largest amount reported and is a crucial number in assessing a company's financial performance"(International Accounting Standards Board, 2011, p. 5). U.S. GAAP revenue standards are lengthy, complex, industry specific, inconsistent, contain quantitative thresholds, examples, scope restrictions, treatment exceptions, and detailed implementation guidance. Altamura, Beatty and Weber (2011) use the reporting requirements imposed by SEC Staff Accounting Bulletin No. 101 to examine how accounting methods that accelerate revenue recognition affect financial reporting. They were specifically examining two ideas - 1) the SEC's concern that allowing revenue recognition prior to completion of the earnings process and 2) the IASBFASB joint project position that inclusion of unearned revenue in earnings provides value-relevant information about future revenue performance. They found some evidence of increased earnings management by firms that accelerate revenue recognition. Caylor (2012) found evidence that managers use judgment in both accrued and deferred revenue to avoid negative earnings surprises. He found little revenue recognition evidence that discretion is used to avoid losses or earnings decreases. His results imply that the revenue-recognition joint project undertaken by the FASB and IASB to reduce managerial estimation in revenue recognition. Linda Devonish (2014) found that an entity is required to present a contract liability, a contract asset, or a receivable in its financial statements once either party to the contract has performed its obligation. Whether an entity presents a contract liability, a contract asset, or a receivable depends on the facts and circumstances. For example, if a customer makes a 
payment before the entity transfers the promised good or service to the customer, the entity must present a contract liability on its balance sheet.

\subsection{Impact of Reporting Revenue Recognition under IFRS}

Murdock predicted active SEC participation in the activities of the TRG: "Revenue is different. Revenue is special. We've invited the firms to come into our offices and share with us how they plan to monitor the implementation of the revenue standard in their practice. Evidence exists to expect that we'll be very proactive, and the door is open, so anybody that wants can come in and talk to us." PricewaterhouseCoopers Partner Dusty Stallings summarized the core principle of the new standard: "You recognize revenue at the amount that you are entitled to as you satisfy the promises that you made in your contract." Although Stallings described this as a "good, sound principle," challenges could arise when trying to determine "the amount that you're entitled to, when you satisfy those promises that you've made, and what those promises that you've made are." Daniel Murdock, deputy chief accountant in the SEC's Office of the Chief Accountant, described the SEC's plan for previous pronouncements now superseded by the revenue recognition standard, such as Staff Accounting Bulletin (SAB) 101: "What's very important for us is to evaluate how the application of the standard evolves over time, so the SAB is going to be effective for a number of years. ... But it's a fair presumption that we would eliminate most - if not all — of our guidance, with the caveat that, as practice evolves, we'll see if there's guidance that is necessary." He stressed that "the hard work starts now." (Golden, Murdock, Hauser, 2014). Revenue is one of the largest and most value-relevant items in firms' financial statements. Based on the 'realizable' and the 'earned' criteria of SFAC No. 5 (FASB in Concepts Statement no. 5. Recognition and measurement in financial statements of business enterprises), revenues should reflect both sell price and timing of delivery. Of those two aspects, selling-price estimates are required for revenue recognition when standalone selling prices for products and services are not available. Srivastava (2014), she examined the effects of selling-price estimates in revenue recognition on the contracting and informational roles of financial statements. Particularly, she examined the setting of SOP 97-2 (AICPA in Software revenue recognition. Statement of Position (SOP) 97-2, AICPA, New York) that removed software firms' flexibility to recognize revenues using selling-price estimates. She found that SOP 97-2 implementation did not improve the contracting role of earnings. However, its implementation partly shifted the informational role of financial statements from income-statement to balance-sheet components (Srivastava, 2014). Five Steps to Recognizing Revenue (2014), the article, discusses the five steps accounting firms in the U.S. should take to recognizing revenue. The steps include identifying the contract with a customer, identifying the performance obligations in the contract, and determining the transaction price. The other two steps tackled are allocating the transaction price and recognizing revenue when or as performance obligations are satisfied.

\subsection{Adoption of IFRS by the United States}

Bloom \& Kamm (2014) discussed the converged revenue recognition standard created by the Financial Accounting Standards Board (FASB) and the International Accounting Standards Board (IASB). Topics covered include the advantages of the converged standard, the issuance of the Revenue from Contracts with Customers standard in 2014 and the five-step revenue recognition model that applied to revenue transactions. How to Recognize Revenue (2014), the article focuses on the revenue recognition project of the Financial Accounting Standards Board (FASB) and International Accounting Standards Board (IASB) as discussed during the 13th Annual Financial Reporting Conference on May 1, 2014. Topics discussed include the five criteria in collaborative arrangements according to Ernst \& Young Professor-in-Residence Norman Strauss, the five steps of revenue recognition, and updated disclosure requirements under the revenue recognition standards. Devonish-Mills (2014) overviewed of the important points that accountants must be aware of about the revenue recognition standard issued by the Financial Accounting Standards Board (FASB) and the International Accounting Standards Board (IASB). The steps for recognizing and measuring revenue outline. Also discussed are the importance of qualitative and quantitative disclosures about revenue recognition as well as communication with stakeholders during the implementation of the standard. The IASB-FASB revenue-recognition project is due to finalize over the next year with the result being a shift from a rules-based set of accounting standards to a principles-based standard. The purpose of this research is to examine financial managers' revenue decisions under a principles-based accounting standard compared to a rules-based accounting standard. The experiment included 127 experienced financial managers with an average of 20 years of experience and $82 \%$ at a manager level or above. The results indicate applying rules-based standards provide less accurate revenue decisions. Additionally, there was not a statistically significant difference of judgment required when applying rules-based standards and subjects applying the principles-based standard (McCarthy, M. \& McCarthy, R., 2014).

Paunescu (2015) conducted for the tax inspections carried out between 2005 and 2013 when Romanian Accounting Standards based on the transposed European Accounting Directives. This research is relevant because Romania is one 
of the EU member states, a country applying the European Directives and whose tax system is quasi-dependent on financial accounting (like many other EU countries). Even if all cases investigated involved entities applying domestic regulations in line with European Directives, we will extrapolate our findings to future or past IFRS adopters, by taking into account the differences with possible consequences on taxable profits between RO-GAAP and IFRS. As for the methodology, empirical research methods were used, which in this case consisted of analyzing all relevant tax decisions the author was able to identify on the Romanian tax body's website, decisions involving revenue recognition disputes between entities and tax inspectors.

\section{Hypotheses Development}

An important question left unanswered by the extant literature is what specific accounting information under IFRS has improved the quality of revenue recognition statement and resulted in an overall improvement in earnings' forecasts for the public companies in the U.S.? While the provisions of the new revenue recognition standard are substantially converged under International Financial Reporting Standards (IFRS) and U.S. Generally Accepted Accounting Principles (U.S. GAAP), minor differences continue to exist. As a result, if the changes brought about by IFRS adoption leads to increased uncertainty around the accounting numbers produced under IFRS in the short run, then revenue recognition which is reported consistently under US GAAP and IFRS, should increase in value relevance. The first hypothesis is therefore,

A list of hypotheses related to the research questions includes below. All hypotheses were tested utilizing $t$ - tests of significance on the means of the samples.

Null Hypothesis 1: There is not be a significant difference between firms, at a 0.05 level of significance, in pre-IFRS operating income and post-IFRS operating income

Test Hypothesis 1: There is be a positive significant difference firms, at a 0.05 level of significance, in pre-IFRS operating income and post-IFRS operating income

The financial results for all business industry collected for 3 years prior to this study. The mean of each sub group calculated on the variables of investor return. Then, a $t$-test of significance with a confidence level of $95 \%$ will perform on all variables to test the null hypothesis.

Null Hypothesis 2: There are not be a significant difference between firms, at a 0.05 level of significance, in pre-IFRS operating income and post-IFRS operating income

Test Hypothesis 2: There is a positive significant difference firms, at a 0.05 level of significance, in pre-IFRS operating income and post-IFRS operating income

The financial results for all business industry collected for 3 years prior to this study. The mean of each subgroup calculated on the variables of earnings per share. Then, a $t$-test of significance with a confidence level of $95 \%$ will perform on all variables to test the null hypothesis.

\section{Model Development and Data}

\subsection{Model Construction and Descriptive Statistics}

To examine the value relevance of revenue recognition components pre-IFRS and post-IFRS we compare the coefficients generated by one independent variable from $10-\mathrm{K}$ report to another controlled independent variables, before and after 1 January 2014. By pooling the T-test model for the entire sample period and including variables interacting between our controlled variables and the pre-IFRS adoption period, we determine whether there has been a significant change in the value relevance of revenue recognition components after the adoption of IFRS. These models are experimental studies with using T-test model. External financial data collected on the official database financial statement from January 1, 2012 to December 31, 2014. The first set of comparisons examined the operating income performance pre-IFRS adoption and post-IFRS net income separate for both multinational companies. Three years of financial statement data collected for both groups. The following accounting based measures served as independent variables for purposes of this study and were used as points of comparison: pre-IFRS operating income and post-IFRS operating income. By comparing the means of two independent samples on these measurements through a series of $t$ tests, it was possible to determine in which areas, if any, the first group was outperforming the second group for each separate business entities. By evaluating the group results on these measures as a whole, it will be possible to determine the overall impact of the new revenue recognition standard policy to operating income performance pre-IFRS and post-IFRS operating income in multinational companies in the telecommunication industry. 


\subsection{Instrumentation and Date Collection Procedures}

Our initial sample consists of 100 firms representing companies listed on the SEC at the end of each of the year 2014. Only two firms in our sample chose to investigate our experiment in the public sector. We use the model of the assumption the behavior of the revenue recognition described by (Streaser, 2015). Streaser (2015) said: "The Standard would increase revenue recognized at the inception of the contract by $225 \%$ and reduce the revenue recognized over time by $19 \%$. Accordingly, Company $\mathrm{T}$ will realize accelerated revenue recognition as a result of adopting the new recognition standard". We select the following companies for our experiment Verizon and AT\&T. We will examine the changes of the operating income on the income statement pre-IFRS and after the IFRS adoption for each company. The companies have been selected randomly from the telecommunication sector. Verizon represents the group A and the AT\&T represents the group B. In the group A, we show the income statement pre-IFRS (the actual report as of December 31, 2014). In the group B, we show the income statement with the applied Streaser model assumption for the telecommunication industry. The Streaser model intentionally introduced, and an outcome observed for this study.

The two samples were independent of each other in the sense that they came separate samples containing different sets of individual subjects. The individual measures in Group A were in no way be linked with, or related to any of the individual measures in Group B, and vice versa. The version of a $t$ test examined in these chapters assessed the significance of the difference between the means of two such samples, providing (a) that the two samples randomly drawn from normally distributed populations and (b) that the measures of which the two samples will compose as the equal-interval. TI used a nondirectional research hypothesis due to the expectation of a difference in one direction $\left(\mathbf{M}_{\mathbf{a}}>\mathbf{M}_{\mathbf{b}}\right)$, or the other $\left(\mathbf{M}_{\mathbf{b}}>\mathbf{M}_{\mathbf{a}}\right)$.

The data collection procedure consisted of the following steps:

The mean of a sample randomly drawn from a normally distributed source population belongs to a sampling distribution of the sample means that is also normal in the form. The overall mean of this sampling distribution will be identical with the mean of the source population:

$$
\boldsymbol{\mu}_{\mathrm{M}}=\boldsymbol{\mu}_{\text {source }}
$$

$\boldsymbol{\mu}_{\mathbf{M}}=$ mean of the sampling distribution of the sample means and

$\boldsymbol{\mu}_{\text {source }}=$ mean of the source population. For two samples, each randomly was drawn from a normally distributed source population, the difference between the means of the two samples:

$$
\mathbf{M}_{\mathbf{a}}-\mathbf{M}_{\mathbf{b}}
$$

belong to a sampling distribution that is normal in the form, with an overall mean equal to the difference between the means of the two source populations:

$$
\mu_{\mathrm{M}-\mathrm{M}}=\boldsymbol{\mu}_{\text {source A }}-\mu_{\text {source B }}
$$

where $\mu_{\mathrm{M}-\mathrm{M}=\text { mean of the sampling distribution; }} \boldsymbol{\mu}_{\text {source } \mathrm{A}}=$ mean of the source population; and $\boldsymbol{\mu}_{\text {source B }}=$ mean of the source population.

On the null hypothesis, $\boldsymbol{\mu}_{\text {source A and }} \boldsymbol{\mu}_{\text {source B, are identical, hence }} \boldsymbol{\mu}_{\mathbf{M - M}=0}$

In general, the null hypothesis is the logical antithesis of whatever hypothesis it is that the researcher will search to examine. The research hypothesis will be the two companies in the same business industry have different effects, so the null hypothesis is that they do not have different effects. The variance of the source population, hence also the value of

$\sigma_{\text {M-M }}$, can be arrived at only through estimation. The test of the null hypothesis will perform not with $\mathbf{z}$ but with $\mathbf{t}$ :

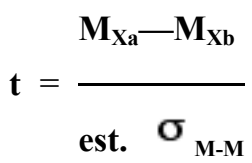

$\mathbf{M}_{\mathbf{X a}}=$ mean of sample A; $\mathbf{M}_{\mathbf{X b}}=$ mean of the sample B and $\boldsymbol{\sigma}_{\mathbf{M}-\mathbf{M}}=$ standard deviation of the sampling distribution.

The resulting value belongs to the particular sampling distribution of $t$ that has defined by $\mathbf{d} \mathbf{f}=\left(\mathrm{N}_{\mathrm{a}}-1\right)+\left(\mathrm{N}_{\mathrm{b}}-1\right)$. To help keep track of where the particular numerical values are coming from beyond this point, here again are the summary statistics for the hypothetical experiment on the effects of two types of groups.

The variance of the source population can estimate as: 


$$
\left\{\mathbf{s}_{\mathrm{p}}^{2}\right\}=\frac{\mathbf{S S}_{\mathbf{a}}+\mathbf{S S}_{\mathbf{b}}}{\left(\mathrm{N}_{\mathrm{a}}-1\right)+\left(\mathrm{N}_{\mathrm{b}}-1\right)}
$$

$\mathbf{S S}_{\mathbf{a}}-$ the mean and sum of squared deviates of the sample A; $\mathbf{S S}_{\mathbf{b}}$ - the mean and sum of squared deviates of the sample B; $\mathbf{N}_{\mathbf{a}}-$ size of simple A; and $\mathbf{N}_{\mathbf{b}}-$ size of simple B

This allows estimating the standard deviation of the sampling distribution of the sample means differences as:

Where $\boldsymbol{\sigma}_{\mathbf{M}-\mathbf{M}}=$ standard deviation of the sampling distribution; $\mathbf{N}_{\mathbf{a}}-$ size of simple A; $\mathbf{N}_{\mathbf{b}}-$ size of simple B; and $\left\{\mathbf{s}_{\mathrm{p}}^{2}\right\}$ source population. With this estimated value of $\sigma_{\mathbf{M}-\mathbf{M}}$ in hand, then it is possible to calculate the appropriate t-ratio as:

$$
\text { est. } \sigma_{\text {M-M }}=\mathbf{s q r t}
$$

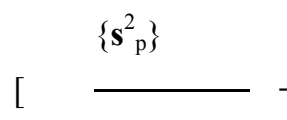

$\mathrm{N}_{\mathrm{a}}$

$$
\mathbf{M}_{\mathbf{X a}}-\mathbf{M}_{\mathbf{X b}}
$$

$=$

where $\mathbf{M}_{\mathbf{X a}}=$ mean of sample A; $\quad \mathbf{M}_{\mathbf{X b}}=$ mean of sample B and $\boldsymbol{\sigma}_{\mathbf{M}-\mathbf{M}}=$ standard deviation of the sampling distribution with $\mathbf{d f}$ - sampling distribution.

In the calculation of a two-sample $\mathbf{t}$-ratio, note that the sign of $\mathbf{t}$ depends on the direction of the difference between $\mathbf{M}_{\mathbf{X a}}$ and $\mathbf{M}_{\mathbf{X b}} \cdot \mathbf{M}_{\mathbf{X}}>\mathbf{M}_{\mathbf{X b}}$ will produce a positive value of $\mathbf{t}$, while $\mathbf{M}_{\mathbf{X a}}<\mathbf{M}_{\mathbf{X b}}$ will produce a negative value of $\mathbf{t}$.

If, on the other hand, the research had begun with no directional hypothesis at all, the effect had been expected as follows:

$$
\text { either } \mathbf{M}_{\mathbf{X a}}>\mathbf{M}_{\mathbf{X b}} \text { or } \mathbf{M}_{\mathbf{X a}}<\mathbf{M}_{\mathbf{X b}}
$$

moreover, that disjunctive expectation ("either one or the other") would have required a nondirectional, two-tailed test. Note that for a nondirectional test the observed value would not be significant at the minimal .05 level.

Refer the calculated value of $t$ to the table of critical values of $t$, with $\mathbf{d f}=\left(\mathrm{N}_{\mathrm{a}}-1\right)+\left(\mathrm{N}_{\mathrm{b}}-1\right)$. A one-tailed directional test will apply only if a specific directional hypothesis stipulated in advance otherwise it will be a nondirectional two-tailed test.

\section{Results}

\subsection{Background Information of the Two Companies}

Verizon Communications Inc. (Verizon or the Company) is a holding company that, acting through its subsidiaries, is one of the world's leading providers of communications, information and entertainment products and services to consumers, businesses and governmental agencies. With a presence around the world, they offer voice, data and video services and solutions on their wireless and wireline networks that are designed to meet customers' demand for mobility, reliable network connectivity, security and control. They have two reportable segments, Wireless and Wireline. Their wireless business, operating as Verizon Wireless, provides voice and data services and equipment sales across the United States using one of the most extensive and reliable wireless networks. Their wireline business provides consumer, business and government customers with communications products and enhanced services, including broadband data and video, corporate networking solutions, data center and cloud services, security and managed network services and local and long distance voice services, and also owns and operates one of the most expansive end-to-end global Internet Protocol (IP) networks. They have a highly skilled, diverse and dedicated workforce of approximately 177,300 employees as of December 31, 2014 (Verizon, 2015). 
AT\&T has more than 120 million wireless customers who have the nation's strongest LTE signal and the nation's most reliable 4G LTE network at their fingertips. Their voice and data network cover more than 99 percent of all Americans, so their customers can stay connected from virtually anywhere - whether they are driving home from work, or driving across the country.

Their AT\&T U-verse ${ }^{\circledR}$ TV and High Speed Internet services are improving how people enjoy entertainment. U-verse TV offers customers more than 600 channels on their home TVs. With a smartphone or tablet, customers can watch 110 live channels outside their home and more than 200 live channels inside their home. U-verse with AT\&T GigaPower $^{\mathrm{SM}}$ is giving customers in select markets the ability to download an HD movie in 36 seconds, a TV episode in three seconds and 25 songs in one second. They are targeting up to 100 cities and municipalities across the country for the expansion of this 1 gigabit per second service (AT\&T, 2015).

\subsection{Basic Financial Information of the Two Companies}

Table 1. Verizon Inc. [dollars in millions]

\section{Consolidated Revenues}

\begin{tabular}{llll}
\hline Years Ended December 31, & 2014 & 2013 & 2012 \\
\hline $\begin{array}{l}\text { Wireless } \\
\quad \text { Service Revenues }\end{array}$ & $\$ 72,630$ & $\$ 69,033$ & $\$ 63,733$ \\
$\quad$ Equipment and other & $\$ 15,016$ & $\$ 11,990$ & $\$ 12,135$ \\
\hline Total & $\$ 87,646$ & $\$ 81,023$ & $\$ 75,868$ \\
\hline
\end{tabular}

Source: Compiled by Author

Table 2. AT\&T Inc. [dollars in millions]

\section{Consolidated Revenues}

\begin{tabular}{llll}
\hline Years Ended December 31, & 2014 & 2013 & 2012 \\
\hline $\begin{array}{l}\text { Wireless } \\
\quad \text { Service Revenues } \\
\text { Equipment and other }\end{array}$ & $\$ 118,437$ & $\$ 119,252$ & $\$ 118,506$ \\
& $\$ 14,010$ & $\$ 9,500$ & $\$ 8,928$ \\
\hline Total & $\$ 132,447$ & $\$ 128,752$ & $\$ 127,434$ \\
\hline
\end{tabular}

\section{Source: Compiled by Author}

\subsection{Revenue Recognition Practice}

The Verizon Wireless segment earns revenue primarily by providing access to and usage of its network. In general, access revenue is billed one month in advance and recognized when earned. Usage revenue billed in arrears and recognized when the service rendered. Equipment sales revenue associated with the sale of wireless handsets and accessories is recognized when the products are delivered to and accepted by the customer, as this is considered to be a separate earnings process from providing wireless services. For agreements involving the resale of third-party services in which they are considered the primary obligor in the arrangements, they record the revenue gross at the time of the sale. For equipment sales, they subsidize the cost of wireless devices for plans under our traditional 
subsidy model. The amount of this subsidy is contingent on the arrangement and terms selected by the customer. In multiple deliverable arrangements that involve the sale of equipment and a service contract, the equipment revenue is recognized up to the amount collected when the wireless device sold (Verizon, 2015).

At\& $T$ revenues derived from wireless, local telephone, long distance, data and video services are recognized when services provided. This based upon either usage (e.g., minutes of traffic/bytes of data processed), period of time (e.g., monthly service fees) or other established fee schedules. Their service revenues are billed either in advance, arrears or are prepaid. Their record revenue reductions for estimated future adjustments to customer accounts, other than bad debt expense, at the time revenue is recognized based on historical experience. Service revenues include billings to their customers for various regulatory fees imposed on us by governmental authorities. They report revenues from transactions between them and their customers net of taxes the government authorities require them to collect from their customers in their consolidated statements of income. Cash incentives given to customers recorded as a reduction of revenue. Revenues and associated expenses related to nonrefundable, upfront service activation and setup fees are deferred and recognized over the associated service contract period or customer life (AT\&T, 2015).

Table 3. Pre-IFRS Revenues compare to Post-IFRS Revenues - Verizon Inc.

Consolidated Revenues

Years Ended December 31, Pre-IFRS Revenue Post-IFRS Revenue

$\begin{array}{lll}2012 & \$ 63,733 & \$ 50,986 \\ 2013 & \$ 69,033 & \$ 55,226 \\ 2014 & \$ 72,630 & \$ 58,104\end{array}$

Source: Compiled by Author

The means of Pre-IFRS Revenue and Post-IFRS Revenue are significantly different at $\mathrm{p}<0.05$

Table 4. Aggregate Pre-IFRS Revenues compare to Post-IFRS Revenues - Verizon Inc. - t- Test

Consolidated Revenues

\begin{tabular}{lll}
\hline Descriptive Statistics & Pre-IFRS Revenue & Post-IFRS Revenue
\end{tabular}

\begin{tabular}{rll}
\hline Mean & 68465.3333 & 54772 \\
Variance & 20030836.3334 & 12821068 \\
Stand. Dev & 4475.5822 & 3580.6519 \\
$\mathrm{~N}$ & 3 & 3 \\
\hline $\mathrm{T}$ & & \\
\hline $\begin{array}{c}\text { Degrees of freedom } \\
\text { Critical Value }\end{array}$ & 4.138 & \\
\hline
\end{tabular}

Source: Compiled by Author

The means of Pre-IFRS Revenue and Post-IFRS Revenue are significantly different at $\mathrm{p}<0.05$ 
The calculated $t$ exceeds the critical value $(4.138>2.776)$, so the means are significantly different based on the table of critical values for two tailed test.

Table 5. Pre-IFRS Revenues compare to Post-IFRS Revenues - AT\&T Inc.

Consolidated Revenues

Years Ended December 31,

Pre-IFRS Revenue

Post-IFRS Revenue

2012

$\$ 118,506$

$\$ 94,805$

2013

$\$ 119,252$

$\$ 95,402$

2014

$\$ 118,437$

$\$ 94,750$

Source: Compiled by Author

The means of Pre-IFRS Revenue and Post-IFRS Revenue are significantly different at $\mathrm{p}<0.05$

Table 6. Aggregate Pre-IFRS Revenues compare to Post-IFRS Revenues - AT\&T Inc. - t- Test

Consolidated Revenues

Descriptive Statistics

Pre-IFRS Revenue

Post-IFRS Revenue

\begin{tabular}{rcc}
\hline Mean & 118731.6667 & 94985.6667 \\
Variance & 204250.3334 & 130756.3334 \\
Stand. Dev & 451.9406 & 361.6025 \\
$\mathrm{~N}$ & 3 & 3 \\
\hline $\mathrm{T}$ & 71.0599 & \\
Degrees of freedom & 4 & \\
Critical Value & 2.776 & \\
\end{tabular}

Source: Compiled by Author

The means of Pre-IFRS Revenue and Post-IFRS Revenue are significantly different at $\mathrm{p}<0.05$

The calculated t exceeds the critical value $(71.0599>2.776)$, so the means are significantly different based on the table of critical values for two tailed test.

\section{Interpretation of Findings}

Research Question 1 is a comparison of pre-IFRS operating income and post-IFRS operating income conducted in Verizon Company to addresses the impact of revenue recognition after the IFRS 15 adoption in the U.S. This figure is the one most commonly used as a benchmark for determining a company's revenue recognition performance. In this study, the author measures the impact of the principle revenue recognition in the company profit performance before and after IFRS 15 adoption in the U.S. The data collected was analyzed using statistical tools.

The means of Pre-IFRS Revenue and Post-IFRS Revenue are significantly different at $\mathrm{p}<0.05$

The calculated $t$ exceeds the critical value $(4.138>2.776)$, so the means are significantly different based on the table of critical values for two tailed test. 
In the study, an analysis of the performance of pre-IFRS operating income performance and post-IFRS operating income performance conducted to addresses the impact of revenue recognition accounting treatment after IFRS adoption undertaken.

Research Question 2 is a comparison of pre-IFRS operating income and post-IFRS operating income conducted in AT\&T Company to addresses the impact of revenue recognition after the IFRS 15 adoption in the U.S. This figure is the one most commonly used as a benchmark for determining a company's revenue recognition performance. In this study, the author measures the impact of the principle revenue recognition in the company profit performance before and after IFRS 15 adoption in the U.S. The data collected was analyzed using statistical tools.

The means of Pre-IFRS Revenue and Post-IFRS Revenue are significantly different at $\mathrm{p}<0.05$

The calculated t exceeds the critical value $(71.0599>2.776)$, so the means are significantly different based on the table of critical values for two tailed test.

In the study, an analysis of the performance of pre-IFRS operating income performance and post-IFRS operating income performance conducted to addresses the impact of revenue recognition accounting treatment after IFRS adoption undertaken.

\section{Recommendations for Future Study}

The United States has been a leader in the revenue recognition area before the International Financial Reporting Standards implementation. Times have changed. The United States is now both a merchandise-importing and capital-importing country; many foreign countries have reached an equal level in international revenue recognition. The world has learned from experience in the United States, how truly complex these factual issues can become. The major industrialized countries are, of course, the most affected in terms of the dollar significance of the underlying revenue recognition transactions. Also, over the past few years international revenue transactions have become a serious issue. The recommendations focused on the substantial restrictions on currency movements in the form of international exchange revenue in most industrialized countries around the World.

\section{Conclusion and Discussion}

The purpose of this study was to presents a summary of the impact of the value relevance of revenue recognition under International Financial Reporting Standards in the United States as guidelines for executives and businessmen of all multinational companies in setting up their revenue recognition new policy to improve their financial statements. The author presented statistical analysis via t-tests and how the value relevance of revenue recognition increase after the IFRS adoption. Currently, the IASB and FASB are approved that the revenue recognition new approach become mandatory for all companies in the public sector in the U.S. and the European Union. We therefore analyze whether revenue recognition new disclosures remain value relevant for a sample of U.S. firms, to test whether revenue recognition statements continue to capture the rich information set reflected in stock prices in an IFRS reporting environment.

The results provide strong evidence that the new revenue recognition standard value relevant under US GAAP and remain value relevant for both public firms after IFRS adoption. Moreover, for public firms we report an increase in the value relevance of revenue account since the adoption of IFRS, and additionally find that revenue recognition disclosures increase in value relevance for the public sector under IFRS. Consequently, if the IASB were to mandate direct revenue recognition statements it would likely provide users of accounts with a valuable incremental source of information. Ultimately, whether the increased value relevance of revenue recognition persists beyond the current market turmoil and the loss of information from the prohibition of internally generated intangibles merits further financial investigation. Regardless of this, we present strong evidence that revenue recognition disclosures are a relevant value source of information in an IFRS reporting environment. Finally, the increase in value revenue will have an impact on the federal taxes from bundled contracts and the companies will pay more tax from the accelerated revenue recognition under the new standard IFRS 15.

\section{References}

Altamuro, J., Beatty, A. L., \& Weber, J. (2005). The effects of accelerated revenue recognition on earnings management and earnings in formativeness: Evidence from SEC staff accounting bulletin no. 101 The Accounting Review, 80(2), 373-401. http://dx.doi.org/10.2308/accr.2005.80.2.373

Ayers, B. C., Jiang, X., \& Yeung, P. E. (2006). Discretionary accruals and earnings management: An analysis of pseudo earnings targets. The Accounting Review, 81(3), 617-652. http://dx.doi.org/10.2308/accr.2006.81.3.617 
Badertscher, B., Collins, D. W., \& Lys, T. (2012). Discretionary accounting choices and the predictive ability of accruals with respect to future cash flows. Journal of Accounting and Economics, 53, 330-352. http://dx.doi.org/10.1016/j.jacceco.2011.11.003

Bloom, R., \& Kamm, J. (2014). REVENUE RECOGNITION. Financial Executive, 30(3), 48-52.

Caylor, M. (2010). Strategic revenue recognition to achieve earnings benchmarks. Journal of Accounting and Public Policy, 29(1), 82. http://dx.doi.org/10.1016/j.jaccpubpol.2009.10.008

Dechow, P., Ge, W., \& Schrand, C. M. (2010). Understanding earnings quality: A review of the proxies, their determinants and their consequences. Journal of Accounting and Economics, 10, 344-401. http://dx.doi.org/10.1016/j.jacceco.2010.09.001

Devonish-Mills, L. (2014). The New Revenue Recognition Standard. Strategic Finance, 96(9), 17-18.

Dyson, R. A. (2015). Case Studies in the New Revenue Recognition Guidance. CPA Journal, 85(3), 22.

Five Steps to Recognizing Revenue. (2014). Journal of Accountancy, 218(1), 44-46.

International Accounting Standards Board. (2011). Discussion paper London, UK: IASB.

Kothari, S. P., Ramanna, K., \& Skinner, D. J. (2010). Implications for GAAP from an analysis of positive research in accounting. Journal of Accounting and Economics, 50, 246-286. http://dx.doi.org/10.1016/j.jacceco.2010.09.003

McCarthy, M., \& McCarthy, R. (2014). Financial Statement Preparers' Revenue Decisions: Accuracy in Applying Rules-Based Standards and the IASB-FASB Revenue Recognition Model. Journal Of Accounting \& Finance (2158-3625), 14(6), 21-43.

PĂUNESCU, M. (2015). Revenue Recognition and Measurement. Accounting Principles vs. Tax Rules for Romanian Entities. Audit Financiar, 13(121), 81-90.

Prakash, R., \& Sinha, N. (2012). Deferred revenues and the matching of revenues and expenses. Contemporary Accounting Review, 30(2), 517-548. http://dx.doi.org/10.1111/j.1911-3846.2012.01164.x

Srivastava, A. (2014). Selling-price estimates in revenue recognition and the usefulness of financial statements. Review Of Accounting Studies, 19(2), 661-697. http://dx.doi.org/10.1007/s11142-013-9263-6

Tsakumis, G.T., Doupnik, T.S., \& Agoglia, C.P. (2011). Principles-based versus rules-based Accounting standards: The influence of standard precision and audit committee strength on financial reporting decisions. The Accounting Review, 86(3), 747-767. http://dx.doi.org/10.2308/accr.00000045

Wüstemann, J., \& Wüstemann, S. (2010). Why Consistency of Accounting Standards Matters: A Contribution to the Rules-Versus-Principles Debate in Financial Reporting. Abacus, 46(1), 1. http://dx.doi.org/10.1111/j.1467-6281.2010.00304.x

Zang, A. Y. (2012). Evidence on the trade-off between real activities manipulation and accrual-based earnings management. The Accounting Review, 87(2), 675-703. http://dx.doi.org/10.2308/accr-10196 